\title{
Quality of Life and Burden of Lung Cancer Patients' Caregivers: A Cross-Sectional Study from Southern Thailand
}

\author{
Orapan Fumaneeshoat, M.D., Thammasin Ingviya, M.D., Ph.D.
}

Department of Family and Preventive Medicine, Faculty of Medicine, Prince of Songkla University, Hat Yai, Songkhla 90110, Thailand.

Received 20 September 2019 • Revised 13 February 2020 • Accepted 21 February 2020 • Published online 30 April 2020

\begin{abstract}
:
Objective: To measure the Quality of Life (QoL) and Caregiver Burden Scale (CBS) of lung cancer patients' caregivers and assess the associated factors.

Material and Methods: This was a cross-sectional study. We interviewed lung cancer patients and their caregivers who were visiting the outpatient department of a tertiary hospital in Thailand. QoL was measured by the World Health Organization Quality of Life-BREF-THAI. CBS was measured by Zarit's burden interview. The data were collected using the KoBoToolbox application. Multivariate ordinal logistic regression was used to assess associations between caregivers' QoL and CBS with the dependent variables, including patient and caregiver factors.
\end{abstract}

Results: Two hundred and four patients and 202 caregivers were included in the study. The only caregivers factor associated with lower QoL was younger age [odds ratio $(O R)=0.33$, 95\% confidence interval $(\mathrm{Cl})$ : 0.11-0.95)] while factors associated with better $\mathrm{QoL}$ were income $(\mathrm{OR}=3.91,95 \% \mathrm{Cl}: 1.13-14.50)$ and being a child of the patient $(\mathrm{OR}=3.24$, 95\% Cl: 1.02-11.30). The main caregivers factor associated with a lower CBS was being Muslim (OR=0.16, 95\% Cl: 0.05-0.52), and the main factor associated with a higher CBS was income (OR=6.12, 95\% Cl: 1.66-23.75). The patients factors affecting CBS were female $(\mathrm{OR}=0.36,95 \% \mathrm{Cl}$ : 0.17-0.71), Barthel's activity daily living (ADL) index (OR= 7.42, 95\% Cl: 1.99-28.65), and $\geq 2$ years looking after a patient (OR=0.40, 95\% Cl: 0.18-0.88).

Conclusion: The factors affecting caregivers' QoL and CBS were their patients' ADL and years with disease. Training on caring patients to maintain the patients' ADL for caregivers should be provided. Health authorities should provide opportunities for patients to share their experience on how they live and cope with the symptoms of lung cancer.

Keywords: associated factors, caregivers, caregiver burden, lung cancer, quality of life

Contact: Orapan Fumaneeshoat, M.D.

Department of Family and Preventive Medicine, Faculty of Medicine,

Prince of Songkla University, Hat Yai, Songkhla 90110, Thailand.

E-mail: orfp_1187@hotmail.com

This is an open access article under the CC BY-NC-ND license

(http://www.jhsmr.org/index.php/jhsmr/about/editorialPolicies\#openAccessPolicy).

J Health Sci Med Res 2020;38(3):177-192 doi: $10.31584 /$ jhsmr.2020736 www.jhsmr.org 


\section{Introduction}

In recent years the number of people with cancer has been increasing worldwide ${ }^{1}$, and cancer has been the leading cause of death over accidents and heart disease since $2000 .^{2}$ Lung cancer is the most serious cancer in men and third in women. ${ }^{3}$

Caregivers, the main supporters of people who suffer from cancer, do not only take care of the patients, but also take part in the patients' decisions. ${ }^{4}$ Therefore, cancer does not affect only the patient but also their caregivers. ${ }^{5}$ The quality of life (QoL) of any person necessarily reflects their physical health, psychological state, personal beliefs, social relationships and their relationships to salient features of their environment. ${ }^{6}$ Aside from quality of life of both patients and caregivers, the patient's treatment can include surgeries, chemotherapies and/or radiotherapies, depending on the stage and complications of the disease. ${ }^{7}$ As the cancer progresses, caregivers will be required to take more responsibilities, including longer times of home care and more frequent hospital visits, resulting in increased caregivers' burden and eventually jeopardizing their quality of life. ${ }^{8}$

Patients with lung cancer may need special attention compared to patients with other cancers. The prevalence of various serious QoL symptoms including hemoptysis (20.0\%), dyspnea (48.0-69.0\%), pain (25.0$50.0 \%)$ and cancer fatigue syndrome $(70.0 \%)$ was higher in patients with lung cancer than those with other cancers such as breast cancer. These symptoms can make the patient suffer and cause a high burden for caregivers. In addition, lung cancer is more difficult to detect than other cancers, resulting in most cases being diagnosed in the late stage. $^{9}$

Caregivers' quality of life can be affected by various factors, including underlying diseases or stage of lung cancer of their patient, hours of caregiving per day, their age, income, level of education, personal relationships that may suffer from their duties, and religion. ${ }^{8}$
Various studies have examined the quality of life of caregivers' patients. ${ }^{10,11}$ However, there are few studies which have examined the QoL and burdens of the caregivers and the associated factors, especially for lung cancer patients. ${ }^{12}$ None of these studies have been done in Southern Thailand, with unique cultures and religious diversity. Therefore, our study examined how taking care of lung cancer patients affects the quality of life and burden of the caregivers in the context of southern Thailand.

Our goals were to measure the QoL and caregiver burden scale (CBS) of lung cancer patients' caregivers and assess the associated factors.

\section{Material and Methods}

Our research protocol was approved by the Ethics Review Committee for the Approval of Research in Human Subjects, Faculty of Medicine, Prince of Songkla University, Thailand (REC 59-321-09-1). The study was a crosssectional study conducted in the Pulmonary Medicine Outpatient Department, the Chemotherapy Center, and the Radiotherapy Center of Songklanagarind Hospital during the $3^{\text {rd }}-17^{\text {th }}$ December 2018 . Lung cancer patients and their primary caregivers were recruited through convenience sampling. Patients and caregivers who visited one of the study centers and agreed to complete the questionnaire were invited to participate in the study. In cases where more than one caregiver was accompanying the patient, we selected the one who had spent the longest time with the patient. We excluded patients and caregivers who could not speak Thai.

We calculated the necessary sample size using the formula to estimate one sample mean. The margin of error was set at 0.1 . The mean primary caregiver's quality of life was assumed at 0.5 , according to the study of Awadalla et al. $^{13}$, which used a similar questionnaire as our study. The required sample size was at least 97 patients and 97 caregivers. 
We used a face-to-face interview questionnaire to collect the data. The questionnaire was divided into two parts.

The first part of the questionnaire for the lung cancer patients consisted of patient demographics including age, gender, religion, educational status, employment status, monthly income, age at lung cancer diagnosis, duration of known lung cancer and completion of the Barthel Activities of Daily Living Index (Barthel $A D L)$.

The second part of the questionnaire was the Primary Caregiver section, which consisted of three subsections. The first section was the caregivers' demographics including age, gender, religion, marital status, educational status, occupation, monthly income, caregiverpatient relationship, period of care, and underlying diseases.

The second section was the World Health Organization Quality of Life-BREF-THAI (WHOQoL-BREF-THAI) instrument for measuring the quality of life of a lung cancer patient's caregiver(s). The WHOQoL-BREF-THAI has 26 items, including two items concerning overall quality of life and general health and 24 items exploring satisfaction. This section covers four domains: physical health (7 items), psychological health (6 items), social relationships (3 items) and environmental health (8 items). Each item is rated on a 5 -point Likert scale from 1 to 5 . The mean score of items within each domain is used to calculate the domain score and transformed to 4-10 scores and 0-100 scores according to the questionnaire guidelines. Higher scores denote higher quality of life. ${ }^{14}$ The reliability of the WHOQOL-BREF-THAI has been officially approved by the WHO with a Cronbach's alpha coefficient of 0.841 and a content validity index of $0.652 .^{15}$

The third section was the CBS for measuring caregiver burden. The CBS contains 22 items which can be divided into four domains: personal strain (9 items), privacy conflicts (4 items), guilt (5 items) and uncertain attitude (4 items). The personal strain examines stressful, depressive and/or anxiety feelings the caregiver feels from taking care of their patient. Privacy conflicts arise when the caregiver has no time to join in community events or meet friends and cannot comfortably manage their life. Guilt results when the caregiver feels they are not taking good enough care of their patient. And the uncertain attitude is the feeling of caregivers that the patient needs them all the time, fear of the future of the patients and fear of inadequate money to meet the patient's needs. ${ }^{16}$ Each item is rated on a 4 point Likert scale from 1 (not at all) to 4 (often), and the ratings of the 22 items are summed. The total score represents the severity of the caregiver's burden, which can be separated into four levels of severity: 0 to 20 little or no burden, 21 to 40 mild to moderate burden, 41 to 60 moderate to severe burden and 61 to 88 severe burden. ${ }^{17}$ The CBS we used was a Thai burden interview questionnaire for caregivers of patients with chronic illness from the Faculty of Nursing of Burapha University which was translated from the English Zarit Burden Interview. The Cronbach's alpha coefficient of the tool was 0.92 . The Cronbach alpha coefficients of each domain: personal strain, privacy conflicts, guilt and uncertain attitude, were 0.90, 0.86, 0.78 and 0.72 , respectively. ${ }^{16}$

The data were collected using the KoBoToolbox web application which allows the users to create their own questionnaire form and collect the data using the form online by storing the data on a cloud server. Then data analyses were done with $R$ version 3.5 .1 and $R$ studio software (R Core Team, Austria). The data were described by frequency, percentage, median and range as applicable. For inferential statistics, we used multivariate ordinal logistic regression to assess the associations between our outcomes including caregivers' QoL and CBS with the dependent variables, including both patients' and caregivers' factors because the outcomes were ordinal 
variables. For missing data, we used the mean imputation method. We used the backward stepwise method based on the lowest Akaike Information Criterion (AIC) in order to select the variables potentially associated with the QoL and CBS of the caregivers in the final model.

\section{Results}

\section{Patients' and caregivers' demographic factors}

We interviewed 204 lung cancer patients and 202 caregivers. Of the 204 patients 134 were men (65.7\%) and 70 were women (34.3\%) with a median age of 57 (range: 21-83) years. Most were Buddhist (82.8\%) followed by Muslim (16.7\%). Eighty point four percent were married, and $36.3 \%$ had a primary school education.
The top three occupational statuses were unemployed $(27.0 \%)$, agricultural work (17.2\%), and government employee (16.2\%). The most common range of income was less than 5,000 baht/month (19.6\%). The median age at the diagnosis of lung cancer was 56 years and the median years with lung cancer was 1 year. Most patients had a Barthel ADL rating of social-bound (87.7\%) (Table 1).

Of the 202 caregivers, 52 were men (25.7\%) and 150 were women $(74.3 \%)$. Their median age was 46 (range: 15-78) years and most were Buddhist (80.7\%) and married (79.7\%). The most common highest level of education was secondary school $(30.2 \%)$. The top three occupations were industrial and rural worker (22.3\%),

Table 1 Demographic factors of patients and caregivers

\begin{tabular}{|c|c|c|c|c|}
\hline \multirow{2}{*}{ Factor } & \multicolumn{2}{|c|}{ Patients $(n=204)$} & \multicolumn{2}{|c|}{ Caregivers $(n=202)$} \\
\hline & Number & $\%$ & Number & $\%$ \\
\hline Age (years) & \multicolumn{2}{|l|}{57} & \multicolumn{2}{|l|}{46} \\
\hline Median (range) & \multicolumn{2}{|c|}{$(21.0-83.0)$} & \multicolumn{2}{|l|}{$(1.5-78.0)$} \\
\hline \multicolumn{5}{|l|}{ Sex } \\
\hline Male & 134 & 65.7 & 52 & 25.7 \\
\hline Female & 70 & 34.3 & 150 & 74.3 \\
\hline \multicolumn{5}{|l|}{ Religion } \\
\hline Buddhist & 169 & 82.8 & 163 & 80.7 \\
\hline Christian & 1 & 0.5 & 0 & 0.0 \\
\hline Muslim & 34 & 16.7 & 38 & 18.8 \\
\hline No religion & 0 & 0.0 & 0 & 0.0 \\
\hline Other & 0 & 0.0 & 0 & 0.0 \\
\hline \multicolumn{5}{|l|}{ Marital status } \\
\hline Single & 17 & 8.3 & 33 & 26.3 \\
\hline Married & 164 & 80.4 & 161 & 79.7 \\
\hline Divorced/widow/separated & 23 & 11.3 & 7 & 3.5 \\
\hline \multicolumn{5}{|l|}{ Level of education } \\
\hline Uneducated & 8 & 3.9 & 2 & 1.0 \\
\hline Lower than primary school & 7 & 3.4 & 3 & 1.5 \\
\hline Primary school & 74 & 36.3 & 45 & 22.3 \\
\hline Secondary school & 44 & 21.6 & 61 & 30.2 \\
\hline Vocational school & 19 & 9.3 & 27 & 13.4 \\
\hline Bachelor's degree & 45 & 22.1 & 51 & 25.2 \\
\hline Higher than bachelor's degree & 7 & 3.4 & 13 & 6.4 \\
\hline
\end{tabular}


Table 1 (continued)

\begin{tabular}{|c|c|c|c|c|}
\hline \multirow{2}{*}{ Factor } & \multicolumn{2}{|c|}{ Patients $(n=204)$} & \multicolumn{2}{|c|}{ Caregivers $(n=202)$} \\
\hline & Number & $\%$ & Number & $\%$ \\
\hline \multicolumn{5}{|l|}{ Occupation } \\
\hline Government employee & 33 & 16.2 & 35 & 17.3 \\
\hline State enterprise & 10 & 4.9 & 3 & 1.5 \\
\hline Businessman & 26 & 12.7 & 40 & 19.8 \\
\hline Industrial or rural worker & 26 & 12.7 & 45 & 22.3 \\
\hline Agriculture & 35 & 17.2 & 30 & 14.9 \\
\hline Student & 0 & 0.0 & 3 & 1.5 \\
\hline Unemployed & 55 & 27.0 & 22 & 10.9 \\
\hline Other & 17 & 8.3 & 16 & 7.9 \\
\hline \multicolumn{5}{|l|}{ Income (baht/month) } \\
\hline No income-1,000 & 38 & 18.6 & 19 & 9.4 \\
\hline $1,000-5,000$ & 40 & 19.6 & 30 & 14.9 \\
\hline $5,000-10,000$ & 35 & 17.2 & 47 & 23.3 \\
\hline $10,001-20,000$ & 34 & 16.7 & 55 & 27.2 \\
\hline $20,001-30,000$ & 26 & 12.7 & 24 & 11.9 \\
\hline$>30,000$ & 28 & 13.7 & 25 & 12.4 \\
\hline \multicolumn{5}{|c|}{ Relationship of caregiver with patient } \\
\hline Parent & & & 7 & 3.5 \\
\hline Sibling & & & 22 & 10.9 \\
\hline Uncle/aunt & & & 3 & 1.5 \\
\hline Spouse (should be first in list\} & & & 91 & 45.0 \\
\hline Child & & & 64 & 31.7 \\
\hline Other & & & 14 & 6.9 \\
\hline \multicolumn{5}{|l|}{ Duration of being caregiver (years) } \\
\hline$<1$ & & & 77 & 42.5 \\
\hline $1-<2$ & & & 56 & 30.9 \\
\hline$>2$ & & & 48 & 26.5 \\
\hline \multicolumn{5}{|l|}{ Caregiving time (hrs/day) } \\
\hline$<24$ & & & 58 & 39.7 \\
\hline 24 & & & 88 & 60.3 \\
\hline \multicolumn{5}{|l|}{ Underlying diseases } \\
\hline Any & & & 50 & 24.8 \\
\hline Diabetes & & & 8 & 1.0 \\
\hline Hypertension & & & 22 & 10.9 \\
\hline Dyslipidemia & & & 10 & 5.0 \\
\hline Myocardial infarction & & & 0 & 0.0 \\
\hline \multicolumn{5}{|l|}{ Barthel ADL } \\
\hline Social-bound & 179 & 87.7 & & \\
\hline Home-bound & 9 & 4.4 & & \\
\hline Bed-bound & 3 & 1.5 & & \\
\hline Age at diagnosis (years) & \multirow{2}{*}{\multicolumn{4}{|c|}{$\begin{array}{l}56 \\
(21.0-81.0)\end{array}$}} \\
\hline Median (range) & & & & \\
\hline Years with lung cancer & \multirow{2}{*}{\multicolumn{4}{|c|}{$\begin{array}{l}1 \\
(0.0-10.0)\end{array}$}} \\
\hline Median (range) & & & & \\
\hline
\end{tabular}

ADL=activity daily living, hrs=hours 
personnel business (19.8\%), and government employee (17.3\%). The largest number had income in the range of 10,000-20,000 baht/month (27.2\%). Most caregivers were partners of their patients (45.0\%). $24.8 \%$ had at least one underlying disease, most commonly diabetes mellitus, hypertension, dyslipidemia or myocardial infarction (Table 1).

Quality of life of caregivers and caregivers' burdens

The WHOQoL-BREF-THAI includes 4 QoL domains, physical, psychological, social relationships and environment. Twenty four of 202 caregivers were not comfortable to answer some parts of the QoL question, resulting in missing data. For the total QoL scores, most caregivers $(55.6 \%)$ said they had a medium quality of life. For the physical domain, $73.2 \%$ of the caregivers had medium quality of life. For the psychological domain, 56.6\% reported a medium quality of life and $42.9 \%$ a high quality of life. For social relationships, $47.9 \%$ had a medium quality of life and $46.3 \%$ had a high quality of life. For the environment domain, $47.5 \%$ had a medium quality of life and $51.0 \%$ had a high quality of life (Table 2 ).

The 4 domains of the CBS include personal strain, privacy conflicts, guilt, and uncertain attitudes. The most common levels of burden in each domain were: $30.3 \%$ of caregivers rated themselves as having a mild to moderate personal strain burden, $62.0 \%$ as having a moderate to severe privacy conflicts burden, $35.5 \%$ as having little to no guilt burden, and $35.8 \%$ as having little to no uncertain attitudes burden. Overall most caregivers (76.4\%) rated themselves as having little or no burden (Table 3).

Table 2 Distribution of caregivers' quality of life scores

\begin{tabular}{|c|c|c|c|c|c|}
\hline \multirow[b]{2}{*}{ Domain } & \multirow[b]{2}{*}{ Median score (range) } & \multicolumn{4}{|c|}{ Number of caregivers (\%) } \\
\hline & & $\begin{array}{l}\text { Low quality } \\
\text { of life }\end{array}$ & $\begin{array}{l}\text { Medium quality } \\
\text { of life }\end{array}$ & $\begin{array}{l}\text { High quality } \\
\text { of life }\end{array}$ & Missing* \\
\hline \multicolumn{6}{|l|}{ Primary caregivers } \\
\hline Physical & $\begin{array}{l}24.0 \\
(22.0-26.0)\end{array}$ & $4(2.1)$ & $142(73.2)$ & $48(24.7)$ & $8(4.0)$ \\
\hline Psychological & $\begin{array}{l}22.0 \\
(20.0-24.0)\end{array}$ & $1(0.5)$ & $111(56.6)$ & $84(42.9)$ & $6(3.0)$ \\
\hline Social relationships & $\begin{array}{l}11.0 \\
(10.0-12.8)\end{array}$ & $11(5.8)$ & $91(47.9)$ & $88(46.3)$ & $12(5.9)$ \\
\hline Environment & $\begin{array}{l}30.0 \\
(26.0-32.0)\end{array}$ & $3(1.5)$ & 95 (47.5) & $102(51.0)$ & $2(1.0)$ \\
\hline Total & $\begin{array}{l}93.0 \\
(86.0-102.8)\end{array}$ & $0(0.0)$ & $99(55.6)$ & $79(44.4)$ & $24(11.9)$ \\
\hline
\end{tabular}

*Participants do not want to answer the questions regarding of quality of life 
Table 3 Distribution of caregiver burden scale scores

\begin{tabular}{lllllll}
\hline & & \multicolumn{5}{c}{ Number of caregivers (\%) } \\
\cline { 3 - 7 } Domain & $\begin{array}{l}\text { Median } \\
\text { (range })\end{array}$ & $\begin{array}{l}\text { Little or no } \\
\text { burden }\end{array}$ & $\begin{array}{l}\text { Mild to moderate } \\
\text { burden }\end{array}$ & $\begin{array}{l}\text { Moderate to } \\
\text { severe burden }\end{array}$ & $\begin{array}{l}\text { Severe } \\
\text { burden }\end{array}$ & Missing \\
\hline Personal strain & $\begin{array}{l}4.0 \\
(1.0-7.3)\end{array}$ & $50(26.6)$ & $57(30.3)$ & $34(18.1)$ & $47(25.0)$ & $14(6.9)$ \\
Privacy conflicts & $\begin{array}{l}1.0 \\
(1.0-3.0)\end{array}$ & $0(0.0)$ & $0(0.0)$ & $121(62.1)$ & $74(38.0)$ & $7(3.5)$ \\
Guilt & $\begin{array}{l}5.0 \\
(2.0-8.0)\end{array}$ & $70(35.5)$ & $35(17.8)$ & $46(23.4)$ & $46(23.4)$ & $5(2.5)$ \\
Uncertain attitude & $\begin{array}{l}2.0 \\
(0.0-4.0)\end{array}$ & $69(35.8)$ & $45(23.3)$ & $38(19.7)$ & $41(21.2)$ & $9(4.5)$ \\
Total & $\begin{array}{l}13.5 \\
(7.0-20.0)\end{array}$ & $136(76.4)$ & $33(18.5)$ & $8(4.5)$ & $1(0.6)$ & $24(11.9)$ \\
\hline
\end{tabular}

Associations between QoL of caregivers and patients' and caregivers' factors

From univariate ordinal logistic regression analysis, only caregivers' monthly income, religion and occupation were found to be associated with their QoL (Supplementary Table 1). Next we performed backward stepwise analysis based on AIC to determine the contribution of factors related with caregivers' QoL. Variables included in the final model are shown in Table 4. We found that caregivers' occupations were related to their overall QoL in consideration of their caregiver's role. Compared with unemployed caregivers, businessmen [odds ratio $(O R)=$ 16.64, 95\% confidence interval $(\mathrm{Cl})$ : 2.12-146.04] and industrial workers (OR=11.43, 95\% Cl: 1.64-91.00) and those who worked in agricultural occupations $(\mathrm{OR}=$ 15.95, 95\% Cl: 1.84-158.35) had higher odds of having a better QoL in the social relations domain. Income was also a factor, as the caregivers who had monthly income between 5,000-10,000 baht and 10,000-20,000 baht had higher odds of having better QoL in the environmental domain than those who had monthly income less than 5,000 baht $(\mathrm{OR}=4.48,95 \% \mathrm{Cl}: 1.16-20.74$ and $\mathrm{OR}=$ 9.86, 95\% Cl: 2.46-48.41, respectively). Compared to a relationship to the patient as a spouse, caregivers who were children of the patients had higher odds of having better QoL (OR=3.24, 95\% Cl: 1.02-11.30). And although the difference was not significant, older caregivers, aged above 45 years, had higher odds of having a better QOL than those aged less than 45 years $(O R=0.33,95 \%$ Cl: 0.11-0.95).

\section{Associations between CBS of caregivers and} patients' and caregivers' factors

From the univariate ordinal logistic regression, sex, Barthel ADL, education level and occupation, monthly income and years with lung cancer of patients were associated with CBS. Female patients were associated with lower CBS in the personal strain and overall domain, compared with male patients. Patients classified as homebound were positively associated with the total score of CBS from all 4 domains, compared with those classified as social-bound. For level of education, patients whose education was primary school or no education were positively associated with higher CBS in the guilt domain, and those with vocational school education were associated with higher CBS in the personal strain and the guilt domain, 
Table 4 Factors associated with quality of life of caregivers by multivariate ordinal logistic regression by stepwise regression based on akaike information criterion

\begin{tabular}{|c|c|c|c|c|c|}
\hline \multirow{2}{*}{ Factor } & \multicolumn{5}{|c|}{ WHOQOL-BREF-THAI } \\
\hline & Physical & Psychological & Social relationships & Environment & Total \\
\hline \multicolumn{6}{|l|}{ Age (years) } \\
\hline$\geq 45$ & Ref & Ref & Ref & Ref & Ref \\
\hline$<45$ & $0.45(0.15-1.29)$ & $0.41(0.13-1.15)$ & $0.13(0.33-0.45)$ & $0.43(0.13-1.28)$ & $0.33(0.11-0.95)$ \\
\hline \multicolumn{6}{|l|}{ Marital status } \\
\hline Married & & Ref & Ref & & \\
\hline Single & & $3.39(0.95-12.53)$ & $3.45(0.84-15.27)$ & & \\
\hline Divorced/widow/ & & $0.20(0.01-6.30)$ & NA & & \\
\hline \multirow{2}{*}{\multicolumn{6}{|c|}{$\begin{array}{l}\text { separated } \\
\text { Level of education }\end{array}$}} \\
\hline & & & & & \\
\hline Primary school & & Ref & & & \\
\hline Secondary school & & $1.58(0.53-4.85)$ & & & \\
\hline Vocational school & & $2.50(0.52-11.84)$ & & & \\
\hline Bachelor's degree & & $0.33(0.08-1.18)$ & & & \\
\hline $\begin{array}{l}\text { Higher than bachelor's } \\
\text { degree }\end{array}$ & & $0.69(0.11-3.65)$ & & & \\
\hline \multicolumn{6}{|l|}{ Occupation } \\
\hline Unemployed & & & Ref & & \\
\hline Government employee & & & $7.69(0.67-90.89)$ & & \\
\hline Private sector employee & & & $0.06(0.00-1.44)$ & & \\
\hline Businessman & & & $16.64(2.12-146.04)$ & & \\
\hline Industrial/rural worker & & & $11.43(1.64-91.00)$ & & \\
\hline Agriculture & & & $15.95(1.84-158.35)$ & & \\
\hline Other & & & $3.96(0.46-35.96)$ & & \\
\hline \multicolumn{6}{|l|}{ Monthly income (baht) } \\
\hline$<5,000$ & & & Ref & Ref & Ref \\
\hline No income & & & $2.39(0.25-24.34)$ & $2.24(0.42-12.76)$ & $1.23(0.25-6.04)$ \\
\hline $5,000-10,000$ & & & $1.25(0.32-5.00)$ & $4.48(1.16-20.74)$ & $1.27(0.37-4.52)$ \\
\hline $10,001-20,000$ & & & $3.05(0.69-14.20)$ & $9.86(2.46-48.41)$ & $3.91(1.13-14.50)$ \\
\hline $20,001-30,000$ & & & $0.16(0.02-1.21)$ & $1.90(0.33-11.43)$ & $0.25(0.03-1.46)$ \\
\hline$>30,000$ & & & $1.49(0.20-11.73)$ & $4.61(0.95-26.00)$ & $1.09(0.24-4.97)$ \\
\hline \multicolumn{6}{|l|}{ Relationship with patient } \\
\hline Spouse & & Ref & Ref & Ref & Ref \\
\hline Parent & & NA & NA & $2.93(0.10-86.51)$ & $1.78(0.06-59.65)$ \\
\hline Sibling & & $0.96(0.19-3.89)$ & $1.12(0.24-5.29)$ & $1.03(0.24-4.30)$ & $0.40(0.05-2.05)$ \\
\hline Child & & $5.40(1.78-18.88)$ & $1.34(3.13-66.35)$ & $5.02(1.48-19.66)$ & $3.24(1.02-11.30)$ \\
\hline Other & & $2.71(0.57-12.97)$ & $2.59(0.47-16.27)$ & $0.46(0.06-2.63)$ & $1.49(0.30-7.31)$ \\
\hline
\end{tabular}

NA=sample size too small to calculate $p$-value, WHOQoL-BREF=World Health Organization Quality of Life-BREF, Ref=reference 
compared with bachelor's degree. For occupation, state enterprise, business owner, and other occupation were associated with lower CBS in uncertain attitude, privacy conflicts and in personal strain respectively, compared with unemployed patients. For the monthly income of patients, the income between 5,000-10,000 baht and no income groups were associated with lower CBS in the privacy conflict domain and total CBS, compared with patients whose income was less than 5,000 baht. Patients who had been diagnosed with lung cancer for 2 years or more showed a significant association with lower total score of CBS, compared with patients who had been diagnosed for less than 1 year.

From the univariate ordinal logistic regression, sex, religion, education level, occupation, monthly income, relationship with patients, underlying diseases and caregiving time of the caregivers were associated with CBS. Male caregivers had lower CBS than females in the guilt domain. Muslim caregivers had lower caregiver burdens than Buddhists for the total CBS. Caregivers who had graduated from primary school showed lower CBS in the privacy conflict domain than those who had graduated from secondary school. Unemployed caregivers showed higher CBS in all domains and total CBS, compared with industrial and rural workers. Caregivers who had no income had higher CBS in all domains and total CBS compared with caregivers whose income was 5,000-10,000 baht. Caregivers who were siblings or children of the patients had lower CBS than those who were spouses in all CBS domains. For underlying diseases, caregivers with dyslipidemia had lower CBS than the caregivers without dyslipidemia. Caregiving time less than 24 hours per day was related to lower CBS in the guilt domain, compared with those looking after their patient for the full 24 hours each day (Supplementary Table 2).

After stepwise selection and multivariate ordinal logistic regression, the factors associated with CBS were sex, Barthel ADL, education level, monthly income, age at diagnosis and years with lung cancer of patients and sex, religion, education level, occupation, monthly income, relationship with patient, underlying diseases and caregiving time of the caregivers. The factors associated with higher CBS were taking care of patients whose Barthel's $\mathrm{ADL}$ was classified as home-bound $(\mathrm{OR}=7.42,95 \% \mathrm{Cl}$ : 1.99-28.65) and being unemployed (OR=9.95, 95\% Cl: 1.16-105.02). Factors associated with lower CBS were Muslim caregivers (OR=0.16, 95\% Cl: 0.05-0.52), taking care of female patients ( $\mathrm{OR}=0.36,95 \% \mathrm{Cl}$ : 0.17-0.71), patients who had monthly income between 5,000-10,000 baht $(\mathrm{OR}=0.18,95 \% \mathrm{Cl}: 0.05-0.59)$ and patients who were diagnosed with lung cancer for more than 2 years (OR=0.4, 95\% Cl: 0.18-0.88).

\section{Discussion}

This study aimed to determine the quality of life of lung cancer patients' caregivers in the perception of the caregivers and patients. The factors associated with QoL of the caregivers could be divided into 3 domains. For the psychological domain, only the relationship with the patient was associated with the QoL. In the social relationship domain, age of caregivers, occupation, relationship with patient and underlying diseases were associated with QoL. For the environment domain, monthly income and relationship with patient were associated with QoL. For the total QoL score, age of caregiver, monthly income, relationship with patient and underlying diseases were associated with QoL. Overall, we found that the relationship of the caregiver with their patient played a major role in the QoL of the patients.

Factors associated with the CBS of caregivers are divided into 4 domains. For the personal strain domain, Barthel's ADL, sex of patient, underlying diseases of caregivers and caregiving time were associated with CBS. For privacy conflicts, Brothel's ADL, monthly income of patients, education level, occupation, monthly income of 
caregivers and caregiving time were related with the CBS. For the guilt domain, Barthel's ADL, education level of patient, age at the diagnosis and sex of caregiver were associated with the CBS. For the uncertain attitude domain, Barthel's ADL, education level, monthly income and underlying diseases of caregiver were associated with the CBS. For the total CBS score, Barthel's $\mathrm{ADL}$, sex of patient, years with lung cancer, religion of caregiver, monthly income of the caregiver and relationship with the patient were associated with the CBS. In conclusion, the Barthel's ADL score of the patient was a good predictor of the caregiver burden.

For QoL, the relationship between a caregiver and the patient they are taking care of has a profound impact on the QoL of the caregiver, especially spouses. A study by $\mathrm{Hu}$ et al. ${ }^{18}$ found that being a spouse of the patient was associated with lower QoL. Another study by Kim et al. ${ }^{19}$ found that at older ages, both patient and caregiver could adapt themselves to situations more easily and develop knowledge and skills to take care of their serious illnesses. Another study by Gangane et al. ${ }^{20}$ found that high monthly income was associated with better QoL.Therefore, the balance between income and cost of living may be a factor associated with QoL which should be explored in future studies.

Our study found that the sex of patients, the mean Barthel's ADL score and age of diagnosis of lung cancer were associated with caregivers' burden. A study by Govina et al. ${ }^{21}$ found that caregivers of male patients reported less favorable caregiving outcomes than those caring for female patients.Another study found that the home-bound group had a higher burden on the caregivers because caring for a disabled individual is much more likely to result in reduced personal time, and consequently, caregivers may find it difficult to relax or to participate in social activities. ${ }^{22}$

The study by $\mathrm{Hu}$ et al. $^{18}$ noted above also found that the age of the patient was related to caregiver burden and the caregiver burden among caregivers for lung cancer patients was inversely related to caregiver social support. In Songkhla, the location of our study, there are many Muslim families, and within the Muslim culture all friends and acquaintances of an ill person are expected to share in providing support to that person, which would thus result in lower CBS in Muslim caregivers as compared to Buddhists (who also care for others in their communities, but not to the level of the Muslims). Many caregivers said that they didn't have enough money to support the patient's treatment and there were additional payments such as travel costs or supportive materials which would result in higher CBS in caregivers with low monthly income. The lifestyle changes of caregivers of lung cancer patients involved disengagement from their regular social and leisure activities, resulting in lowering their quality of life in the social relationships domain. ${ }^{23}$

Our study has various strong points. Paperless data collection using the KoboToolbox application was performed to reduce data recording errors, via reducing potential human error which can occur with paper-based questionnaires when transferring the information from paper forms to a computer. In addition, we used ordinal logistic regression for analysis, which is a rigorous statistical method to assess associations of outcomes which are measured as ordinal variables.

However, our results should be interpreted with caution. The study design was a cross-sectional study, therefore temporal ambiguity was the main limitation. In addition, the study population was from a tertiary hospital in which we have a disproportionately high number of patients with severe conditions who need invasive treatments and interventions. Thus, the QoL of caregivers for these patients might be lower than for general Thai caregivers while the CBS might be higher. Lastly, the questionnaire was subjective, and so the answers would to some extent depend on the emotional state and 
perceptions of the respondent at the time of data collection, and might not have represented their normal state of mind.

\section{Conclusion}

Our study on lung cancer patients and their primary caregivers found that primary caregivers had medium QoL and little to no CBS. Factors associated with QoL and CBS were incomes, underlying diseases of caregivers, patients' ADL and years with disease. The universal healthcare coverage might reduce the healthcare cost and the indirect costs such as transportation can be reduced by referring the patients to local healthcare facilities near the patient's home. Counseling on preventing or managing chronic diseases should be provided to caregivers. Training on caring patients to maintain the patients' ADL for caregivers should be provided. Health authorities should provide opportunities for patients to share their experience on how they live and cope with the symptoms of lung cancer.

\section{Acknowledgement}

This study was supported by the Faculty of Medicine, Prince of Songkla University (REC 59-32109-1). We would like to acknowledge the assistance and support for recruiting lung cancer patients and their caregivers of Dr. Sarayut Lucien Geater. We also would like to thank the $5^{\text {th }}$ year Prince of Songkla University medical students of the class of 2018 for their assistance with interviewing the patients and caregivers and data collection.

\section{Conflict of interest}

The authors confirm that there are no known conflicts of interest associated with this study and there was no significant financial support for this work that could have influenced its outcome.

\section{References}

1. Thakkar J, McCarthy B, Villano L. Age-specific cancer incidence rates that continue to rise through the oldest age groups. Am J Med Sci 2014;348:65-70.

2. Ministry of Public Health. Number and death rate per population 1994-2016 [homepage on the Internet]. Bangkok: Strategy and Planning Division; 2018 [cited 2018 Dec 14]. Available from: http://social.nesdb.go.th/SocialStat/Stat Report_Final.aspx?reportid $=367$ \&template $=1 \mathrm{R} 2 \mathrm{C} \&$ yeartype $=$ M\&subcatid $=15$

3. International Agency for Research on Cancer. Lung fact sheet [homepage on the Internet]. Geneva: WHO; 2018 [cited 2018 Dec 14]. Available from: http://gco.iarc.fr/today/data/ factsheets/cancers/15-Lung-fact-sheet.pdf

4. Caring for the caregiver [homepage on the Internet]. Maryland: National Cancer Institute; 2017 [cited 2018 Dec 14]. Available from: https://www.cancer.gov/publications/ patient-education/caring-for-the-caregiver

5. LeSeure $\mathrm{P}$, Chongkham-ang S. The experience of caregivers living with cancer patients: a systematic review and metasynthesis. J Pers Med 2015;5:406-39.

6. World Health Organization. WHOQOL: measuring quality of life [homepage on the Internet]. Geneva: WHO; 1999 [cited 2018 Dec 14]. Available from: https://www.who.int/ healthinfo/survey/whoqol-qualityoflife/en/

7. American Cancer Society. Treating non-small cell lung cancer [homepage on the Internet]. Atlanta: American Cancer Society; 2018 [cited 2018 Nov 23]. Available from: https:// www.cancer.org/cancer/non-small-cell-lung-cancer/ treating.html

8. Borges L, Franceschini J, Costa D, Fernandes G, Jamnik S, Santoro L. Family caregiver burden: the burden of caring for lung cancer patients according to the cancer stage and patient quality of life. J Bras Pneumol 2017;43:18-23.

9. Ben-Arye E, Samuels N. Patient-centered care in lung cancer: exploring the next milestones. Transl Lung Cancer Res 2015; 4:630-4.

10. Nazlı H, Nadiye O, Elanur Y, Nese E, Behice E. The quality of life of family caregivers of cancer patients in the East of Turkey. Eur J Oncol Nurs 2010;14:181-260

11. Minaya F, Berbis J, Chinot $O$, Auquier P. Assessing the quality of life among caregivers of patients with gliomas. Neurooncol Pract 2014;1:191-7. 
12. Yu H, Li L, Liu C, Huang W, Zhou J, Fu W, et al. Factors associated with the quality of life of family caregivers for leukemia patients in China. Health Qual Life Outcomes 2017; 23:15-55.

13. Awadalla W, Ohaeri U, Gholoum A, Khalid A, Hamad A, Jacob A. Factors associated with quality of life of outpatients with breast cancer and gynecologic cancers and their family caregivers: a controlled study. BMC Cancer 2007;19:7-14.

14. Gholami A, Jahromi LM, Zarei E, Dehghan A. Application of WHOQOL-BREF in measuring quality of life in health-care staff. Int J Prev Med 2013;4:809-17.

15. World Health Organization. WHO I WHOQOL: measuring quality of life [homepage on the Internet]. Geneva: WHO; 1999 [cited 2018 Nov 23]. Available from: http://www.who. int/healthinfo/survey/whoqol-qualityoflife/en/? fbclid= IwAR29qL1Pf4VUAPCjH7Ju-zJbe4wa5WLRidi1zTKcALa_ HG4WuLXr1M4vXgU

16. Toonsiri C, Sunsern R, Lawang W. Development of the burden interview for caregivers of patients with chronic illness. J Nurs Educ 2011;4:62-75.

17. Tan Y, Molassiotis A, Lloyd Williams M, Yorke J. Burden, emotional distress and quality of life among informal caregivers of lung cancer patients: an exploratory study. Eur $\mathrm{J}$ Cancer Care (Engl) 2018;27:36-50.
18. Hu X, Peng X, Su Y, Huang W. Caregiver burden among Chinese family caregivers of patients with lung cancer: a cross-sectional survey. Eur J Oncol Nurs Off J Eur Oncol Nurs Soc 2018;37:74-80.

19. Kim Y, Baker F, Spillers RL. Cancer caregivers' quality of life: effects of gender, relationship, and appraisal. J Pain Symptom Manage 2007;34:294-304.

20. Gangane N, Khairkar P, Hurtig K, Sebastián MS. Quality of life determinants in breast cancer patients in central rural India. Asian Pac J Cancer Prev APJCP 2017;18:3325-32.

21. Govina O, Kotronoulas G, Mystakidou K, Katsaragakis S, Vlachou E, Patiraki E. Effects of patient and personal demographic, clinical and psychosocial characteristics on the burden of family members caring for patients with advanced cancer in Greece. Eur J Oncol Nurs 2015;19:81-8.

22. Du J, Shao S, Jin H, Qian G, Xu W, Lu Q. Factors associated with health-related quality of life among family caregivers of disabled older adults: a cross-sectional study from Beijing. Eur J Cancer Care 2018;27:60-75.

23. Mosher E, Champion L, Azzoli G, Hanna N, Jalal I, Fakiris J, et al. Economic and social changes among distressed family caregivers of lung cancer patients. Support Care Cancer 2013;21:819-26. 
Supplementary Table 1 Factors associated with quality of life of caregivers by univariable ordinal logistic regression

\begin{tabular}{|c|c|c|c|c|c|}
\hline \multirow{2}{*}{ Factor } & \multicolumn{5}{|c|}{ WHOQOL-BREF-THAI } \\
\hline & Physical & Psychological & Social relationships & Environment & Total \\
\hline \multicolumn{6}{|l|}{ Age (years) } \\
\hline$<45$ & Ref & Ref & Ref & Ref & Ref \\
\hline$\geq 45$ & $0.49(0.26-0.91)^{*}$ & $0.84(0.48-1.46)$ & $0.7(0.41-1.19)$ & $0.64(0.37-1.11)$ & $0.56(0.33-0.96)^{\star}$ \\
\hline \multicolumn{6}{|l|}{ Sex } \\
\hline Male & Ref & Ref & Ref & Ref & Ref \\
\hline Female & $1.11(0.56-2.30)$ & $1.04(0.56-1.96)$ & $0.76(0.41-1.42)$ & $0.83(0.44-1.55)$ & $0.76(0.58-1.96)$ \\
\hline \multicolumn{6}{|l|}{ Religion } \\
\hline Buddhist & Ref & Ref & Ref & Ref & Ref \\
\hline Muslim & $0.77(0.34-1.64)$ & $0.47(0.22-0.96)^{*}$ & $0.6(0.30-1.19)$ & $0.33(0.15-0.68)^{*}$ & $0.54(0.27-1.05)$ \\
\hline \multicolumn{6}{|l|}{ Marital status } \\
\hline Married & Ref & Ref & Ref & Ref & Ref \\
\hline Single & $0.95(0.40-2.15)$ & $1.23(0.58-2.58)$ & $0.82(0.40-1.68)$ & $1.56(0.73-3.41)$ & $0.94(0.45-1.93)$ \\
\hline $\begin{array}{l}\text { Divorced/widow/ } \\
\text { separated }\end{array}$ & $1.93(0.40-8.10)$ & $1.86(0.40-9.71)$ & $0.69(0.14-3.28)$ & $0.83(0.18-3.78)$ & $1.21(0.28-5.30)$ \\
\hline \multicolumn{6}{|l|}{ Level of education } \\
\hline Primary school & Ref & Ref & Ref & Ref & Ref \\
\hline Secondary school & $0.73(0.33-1.61)$ & $1.75(0.82-3.76)$ & $1.48(0.73-3.00)$ & $0.95(0.45-2.00)$ & $1.16(0.57-2.37)$ \\
\hline Vocational school & $1.24(0.47-3.21)$ & $2.59(1.02-6.79)$ & $0.96(0.40-1.31)$ & $1.5(0.59-3.88)$ & $1.71(0.71-4.19)$ \\
\hline Bachelor's degree & $0.33(0.13-0.82)$ & $1.29(0.58-2.88)$ & $1.11(0.52-2.36)$ & $1.42(0.65-3.11)$ & 1.07 (0.51-2.27) \\
\hline $\begin{array}{l}\text { Higher than bachelor's } \\
\text { degree }\end{array}$ & $0.42(0.09-1.59)$ & $1.19(0.32-4.11)$ & $0.94(0.29-3.00)$ & $1.91(0.56-7.03)$ & $0.7(0.19-2.32)$ \\
\hline \multicolumn{6}{|l|}{ Occupation } \\
\hline Unemployed & Ref & Ref & Ref & Ref & Ref \\
\hline Government employee & $1.83(0.58-5.32)$ & $2.44(0.86-7.23)$ & $6.81(2.39-20.45)^{*}$ & $3.86(1.35-11.64)^{*}$ & $3.00(1.07-8.69)^{*}$ \\
\hline Private sector employee & $0.36(0.05-2.42)$ & $0.43(0.06-2.23)$ & $1.39(0.31-6.05)$ & $2.07(0.48-9.29)$ & $0.47(0.06-2.39)$ \\
\hline Businessman & $1.61(0.53-5.32)$ & $1.64(0.6-4.66)$ & $2.56(0.96-7.07)$ & $1.97(0.72-5.59)$ & $2.08(0.79-5.78)$ \\
\hline Industrial/rural worker & $1.52(0.51-4.94)$ & $1.11(0.41-3.10)$ & $2.69(1.04-7.21)^{*}$ & $1.82(0.67-5.05)$ & $1.75(0.67-4.79)$ \\
\hline Agriculture & $1.66(0.50-5.81)$ & $1.13(0.38-3.41)$ & $5.55(1.92-16.87)^{\star}$ & $2.35(0.81-7.06)$ & $1.90(0.66-5.65)$ \\
\hline Other & $1.04(0.23-4.42)$ & $2.04(0.59-7.39)$ & $2.65(0.78-9.13)$ & $1.3(0.37-4.62)$ & $1.74(0.52-5.88)$ \\
\hline \multicolumn{6}{|l|}{ Monthly income (baht) } \\
\hline$<5,000$ & Ref & Ref & Ref & Ref & Ref \\
\hline No income & $1.14(0.30-4.09)$ & $1.51(0.44-5.09)$ & $1.48(0.49-4.43)$ & $1.48(0.45-5.17)$ & $0(0.29-2.99)$ \\
\hline $5,000-10,000$ & $2.04(0.77-5.69)$ & $1.64(0.64-4.43)$ & $2.38(1.01-5.71)^{*}$ & $2.38(1.55-11.04)^{\star}$ & $1.76(0.73-4.35)$ \\
\hline $10,001-20,000$ & $0.98(0.36-2.75)$ & $2.54(1.02-6.67)$ & $2.17(0.94-5.15)$ & $2.17(2.39-16.46)^{\star}$ & $2.43(1.03-5.92)^{*}$ \\
\hline $20,001-30,000$ & $1.39(0.42-4.58)$ & $3.12(1.04-9.84)$ & $1.9(0.68-5.41)$ & $1.9(1.63-15.64)^{\star}$ & $2.08(0.74-6.04)$ \\
\hline$>30,000$ & $1.08(0.32-3.59)$ & $2.42(0.81-7.48)$ & $2.84(1.02-8.14)$ & $2.84(1.63-15.64)$ & $1.92(0.68-5.48)$ \\
\hline \multicolumn{6}{|l|}{ Relationship with patient } \\
\hline Spouse & Ref & Ref & Ref & Ref & Ref \\
\hline Parent & $1.11(0.18-5.34)$ & $0.55(0.08-2.72)$ & $1.78(0.36-12.90)$ & $1.73(0.38-9.11)$ & $1.55(0.32-8.24)$ \\
\hline Sibling & $1.47(0.56-3.75)$ & $0.84(0.32-2.09)$ & $0.47(0.18-1.17)$ & $1.32(0.53-3.34)$ & $0.7(0.28-1.70)$ \\
\hline Child & $0.58(0.27-1.20)$ & $1.30(0.69-2.46)$ & $1.69(0.91-3.17)$ & $1.73(0.92-3.31)$ & $0.88(0.48-1.63)$ \\
\hline Other & $0.46(0.12-1.50)$ & $1.26(0.44-3.59)$ & $0.63(0.23-1.70)$ & $1.18(0.43-3.30)$ & $0.6(0.21-1.64)$ \\
\hline \multicolumn{6}{|l|}{ Underlying disease } \\
\hline \multicolumn{6}{|l|}{ Diabetes mellitus } \\
\hline No & Ref & Ref & Ref & Ref & Ref \\
\hline Yes & $1.79(0.39-7.01)$ & $0.84(0.17-3.51)$ & $0.74(0.22-2.42)$ & $1.85(0.45-9.19)$ & $1.63(0.47-5.89)$ \\
\hline
\end{tabular}


Supplementary Table 1 (continued)

\begin{tabular}{|c|c|c|c|c|c|}
\hline \multirow{2}{*}{ Factor } & \multicolumn{5}{|c|}{ WHOQOL-BREF-THAI } \\
\hline & Physical & Psychological & Social relationships & Environment & Total \\
\hline \multicolumn{6}{|c|}{ Hypertension } \\
\hline No & Ref & Ref & Ref & Ref & Ref \\
\hline Yes & $2.38(0.95-5.77)$ & $0.62(0.23-1.54)$ & $1.36(0.59-3.16)$ & $1.37(0.57-3.38)$ & $1.49(0.64-3.50)$ \\
\hline \multicolumn{6}{|c|}{ Dyslipidemia } \\
\hline No & Ref & Ref & Ref & Ref & Ref \\
\hline Yes & $1.54(0.35-5.67)$ & $0.94(0.23-3.39)$ & $1.11(0.34-3.67)$ & $1.12(0.32-4.07)$ & $1.05(0.29-3.64)$ \\
\hline \multicolumn{6}{|c|}{$\begin{array}{l}\text { Duration of being caregiver } \\
\text { (years) }\end{array}$} \\
\hline$\geq 1$ & Ref & Ref & Ref & Ref & Ref \\
\hline$<1$ & $1.12(0.59-2.13)$ & $0.98(0.54-1.75)$ & $1.04(0.59-1.82)$ & $0.70(0.39-1.26)$ & $0.99(0.56-1.74)$ \\
\hline \multicolumn{6}{|c|}{ Caregiving time (hrs/day) } \\
\hline$\geq 24$ & Ref & Ref & Ref & Ref & Ref \\
\hline$<24$ & $1.24(0.53-2.81)$ & $1.11(0.50-2.43)$ & $0.51(0.23-1.07)$ & $0.91(0.42-1.99)$ & $0.70(0.31-1.51)$ \\
\hline
\end{tabular}

${ }^{*} \mathrm{p}$-value $<0.05$

Ref=reference, WHOQoL-BREF=World Health Organization Quality of Life-BREF, hrs=hours

Supplementary Table 2 Factors associated with caregiver burden scale by univariable ordinal logistic regression

\begin{tabular}{|c|c|c|c|c|c|}
\hline \multirow{2}{*}{ Factor } & \multicolumn{5}{|c|}{ Caregiver burden scale } \\
\hline & Personal strain & Privacy conflict & Guilt & Uncertain attitude & Total \\
\hline \multicolumn{6}{|l|}{ Patient factors } \\
\hline \multicolumn{6}{|l|}{ Age (years) } \\
\hline$<60$ & Ref & Ref & Ref & Ref & Ref \\
\hline$\geq 60$ (as earlier) & $0.85(0.50-1.45)$ & $1.07(0.62-1.84)$ & $0.89(0.53-1.50)$ & $0.66(0.39-1.10)$ & $0.76(0.43-1.35)$ \\
\hline \multicolumn{6}{|l|}{ Sex } \\
\hline Male & Ref & Ref & Ref & Ref & Ref \\
\hline Female & $0.52(0.30-0.88)$ & $1.00(0.58-1.70)$ & $0.73(0.44-1.22)$ & $0.79(0.47-1.31)$ & $0.37(0.20-0.66)$ \\
\hline \multicolumn{6}{|l|}{ Religion } \\
\hline Buddhist & Ref & Ref & Ref & Ref & Ref \\
\hline Muslim & $1.15(0.60-2.19)$ & $1.37(0.70-2.68)$ & $0.88(0.46-1.69)$ & $1.10(0.57-2.13)$ & $0.71(0.35-1.45)$ \\
\hline \multicolumn{6}{|l|}{ Barthel ADL } \\
\hline Social-bound & Ref & Ref & Ref & Ref & Ref \\
\hline Home-bound & $2.36(0.83-6.86)$ & $2.04(0.65-6.34)$ & $2.32(0.86-6.41)$ & $2.11(0.75-6.04)$ & $5.05(1.76-14.65)$ \\
\hline \multicolumn{6}{|l|}{ Marital status } \\
\hline Married & Ref & Ref & Ref & Ref & Ref \\
\hline Single & $1.29(0.53-3.13)$ & $1.02(0.38-2.64)$ & $1.18(0.50-2.81)$ & $2.24(0.94-5.49)$ & $1.37(0.50-3.72)$ \\
\hline Divorced/widow/separated & $0.65(0.29-1.48)$ & $0.76(0.32-1.72)$ & $0.74(0.33-1.64)$ & $0.96(0.43-2.11)$ & $0.68(0.29-1.60)$ \\
\hline \multicolumn{6}{|l|}{ Level of education } \\
\hline Bachelor's degree & Ref & Ref & Ref & Ref & Ref \\
\hline Uneducated & $0.59(0.14-2.44)$ & $1.04(0.27-3.80)$ & $1.47(0.40-5.30)$ & $0.51(0.12-2.06)$ & $0.87(0.19-4.02)$ \\
\hline Lower than primary school & $2.23(0.56-9.24)$ & $0.62(0.12-2.58)$ & $6.28(1.34-34.64)$ & $3.19(0.67-15.66)$ & $2.67(0.57-12.14)$ \\
\hline Primary school & $1.03(0.53-2.04)$ & $0.76(0.39-1.51)$ & $1.61(0.84-3.12)$ & $1.49(0.79-2.85)$ & $1.93(0.94-4.02)$ \\
\hline
\end{tabular}


Supplementary Table 2 (continued)

\begin{tabular}{|c|c|c|c|c|c|}
\hline \multirow{2}{*}{ Factor } & \multicolumn{5}{|c|}{ Caregiver burden scale } \\
\hline & Personal strain & Privacy conflict & Guilt & Uncertain attitude & Total \\
\hline Secondary school & $1.48(0.71-3.10)$ & $0.52(0.23-1.15)$ & $1.43(0.70-2.93)$ & $1.18(0.58-2.43)$ & $1.50(0.67-3.35)$ \\
\hline Vocational school & $3.15(1.16-8.69)$ & $1.62(0.61-4.26)$ & $2.90(1.11-7.75)$ & $1.81(0.69-4.81)$ & $1.81(0.60-5.50)$ \\
\hline $\begin{array}{l}\text { Higher than bachelor's } \\
\text { degree }\end{array}$ & $1.63(0.32-8.60)$ & $1.70(0.36-7.61)$ & $0.72(0.13-3.47)$ & $1.19(0.30-4.42)$ & $4.01(0.85-18.03)$ \\
\hline \multicolumn{6}{|l|}{ Occupation } \\
\hline Unemployed & Ref & Ref & Ref & Ref & Ref \\
\hline Government employee & $0.84(0.37-1.91)$ & $0.88(0.39-1.97)$ & $0.58(0.27-1.24)$ & $0.77(0.36-1.63)$ & $1.26(0.54-2.94)$ \\
\hline State enterprises & $0.46(0.14-1.46)$ & $0.75(0.22-2.36)$ & $0.43(0.14-1.25)$ & $0.30(0.09-0.93)$ & $0.47(0.14-1.63)$ \\
\hline Businessman & $0.43(0.18-1.00)$ & $0.34(0.13-0.84)$ & $1.30(0.57-2.96)$ & $0.84(0.37-1.93)$ & $0.43(0.17-1.10)$ \\
\hline Industrial/rural worker & $0.61(0.25-1.47)$ & $0.68(0.28-1.63)$ & $0.88(0.38-2.03)$ & $0.68(0.29-1.57)$ & $1.22(0.49-3.05)$ \\
\hline Agriculture & $0.79(0.37-1.68)$ & $0.46(0.20-1.02)$ & $0.74(0.34-1.61)$ & $0.65(0.30-1.39)$ & $0.68(0.29-1.58)$ \\
\hline Other & $0.31(0.11-0.86)$ & $0.77(0.28-2.09)$ & $0.65(0.24-1.69)$ & $0.54(0.20-1.42)$ & $0.80(0.27-2.31)$ \\
\hline \multicolumn{6}{|l|}{ Monthly income (baht) } \\
\hline$<5,000$ & Ref & Ref & Ref & Ref & Ref \\
\hline No income & $0.53(0.23-1.21)$ & $1.23(0.53-2.84)$ & $0.74(0.33-1.66)$ & $0.69(0.31-1.54)$ & $0.41(0.17-0.97)$ \\
\hline $5,000-10,000$ & $0.61(0.26-1.40)$ & $0.26(0.09-0.70)$ & $0.79(0.34-1.84)$ & $0.83(0.36-1.94)$ & $0.63(0.26-1.49)$ \\
\hline $10,001-20,000$ & $0.62(0.27-1.44)$ & $1.33(0.57-3.15)$ & $0.57(0.25-1.28)$ & $0.74(0.33-1.68)$ & $0.45(0.18-1.11)$ \\
\hline $20,0001-30,000$ & $0.79(0.31-2.02)$ & $1.19(0.47-3.00)$ & $0.54(0.22-1.28)$ & $0.70(0.30-1.66)$ & $0.45(0.17-1.18)$ \\
\hline$>30,000$ & $0.48(0.19-1.20)$ & $0.96(0.38-2.40)$ & $0.51(0.21-1.21)$ & $0.53(0.22-1.25)$ & $0.52(0.20-1.33)$ \\
\hline \multicolumn{6}{|l|}{ Age at the diagnosis (years) } \\
\hline$\geq 56$ & Ref & Ref & Ref & Ref & Ref \\
\hline$<56$ & $1.15(0.68-1.94)$ & $1.27(0.74-2.19)$ & $1.48(0.89-2.47)$ & $1.12(0.67-1.88)$ & $1.08(0.62-1.90)$ \\
\hline \multicolumn{6}{|l|}{ Years with disease (years) } \\
\hline$<1$ & Ref & Ref & Ref & Ref & Ref \\
\hline $1-<2$ & $0.90(0.47-1.69)$ & $0.83(0.42-1.63)$ & $0.94(0.50-1.78)$ & $0.79(0.42-1.47)$ & $0.93(0.48-1.82)$ \\
\hline$\geq 2$ & $0.68(0.35-1.32)$ & $1.46(0.76-2.80)$ & $1.15(0.62-2.13)$ & $0.78(0.42-1.46)$ & $0.37(0.18-0.76)$ \\
\hline \multicolumn{6}{|l|}{ Caregiver factors } \\
\hline \multicolumn{6}{|l|}{ Age (years) } \\
\hline$\geq 45$ (as earlier) & Ref & Ref & Ref & Ref & Ref \\
\hline$<45$ & $0.85(0.50-1.45)$ & $1.04(0.58-1.87)$ & $1.07(0.63-1.82)$ & $1.31(0.77-2.23)$ & $0.81(0.43-1.50)$ \\
\hline \multicolumn{6}{|l|}{ Sex } \\
\hline Female & Ref & Ref & Ref & Ref & Ref \\
\hline Male & $0.56(0.30-1.04)$ & $0.67(0.33-1.31)$ & $0.44(0.23-0.82)$ & $0.75(0.41-1.36)$ & $0.75(0.37-1.49)$ \\
\hline \multicolumn{6}{|l|}{ Religion } \\
\hline Buddhist & Ref & Ref & Ref & Ref & Ref \\
\hline Muslim & $1.06(0.55-2.05)$ & $1.61(0.79-3.22)$ & $0.95(0.48-1.86)$ & $1.17(0.60-2.32)$ & $0.42(0.18-0.94)$ \\
\hline \multicolumn{6}{|l|}{ Marital status } \\
\hline Married & Ref & Ref & Ref & Ref & Ref \\
\hline Single & $0.64(0.32-1.26)$ & $1.10(0.52-2.26)$ & $1.11(0.56-2.20)$ & $1.15(0.59-2.21)$ & $1.11(0.51-2.39)$ \\
\hline \multicolumn{6}{|l|}{ Level of education } \\
\hline Secondary school & Ref & Ref & Ref & Ref & Ref \\
\hline Primary school & $0.98(0.47-2.03)$ & $0.39(0.16-0.88)$ & $0.92(0.44-1.90)$ & $0.65(0.30-1.65)$ & $0.60(0.25-1.43)$ \\
\hline Vocational school & $0.59(0.25-1.42)$ & $0.63(0.23-1.64)$ & $0.69(0.28-1.70)$ & $0.52(0.21-1.25)$ & $0.73(0.26-2.02)$ \\
\hline Bachelor's degree & $0.61(0.29-1.27)$ & $0.66(0.30-1.43)$ & $0.73(0.35-1.51)$ & $0.81(0.39-1.65)$ & $0.88(0.38-2.03)$ \\
\hline $\begin{array}{l}\text { Higher than Bachelor's } \\
\text { degree }\end{array}$ & $1.60(0.54-4.89)$ & $1.32(0.38-4.41)$ & $0.82(0.26-2.46)$ & $0.52(0.18-1.48)$ & $1.34(0.39-4.46)$ \\
\hline
\end{tabular}


Supplementary Table 2 (continued)

\begin{tabular}{|c|c|c|c|c|c|}
\hline \multirow{2}{*}{ Factor } & \multicolumn{5}{|c|}{ Caregiver burden scale } \\
\hline & Personal strain & Privacy conflict & Guilt & Uncertain attitude & Total \\
\hline \multicolumn{6}{|l|}{ Occupation } \\
\hline Industrial/rural worker & Ref & Ref & Ref & Ref & Ref \\
\hline Unemployed & $3.69(1.43-9.90)$ & $3.10(1.18-8.36)$ & $2.62(1.04-6.71)$ & $4.46(1.68-12.25)$ & $6.11(2.03-18.74)$ \\
\hline Government employee & $1.01(0.44-2.28)$ & $0.88(0.35-2.20)$ & $0.75(0.33-1.70)$ & $1.02(0.45-2.31)$ & $1.72(0.65-4.59)$ \\
\hline Businessman & $1.14(0.50-2.59)$ & $0.70(0.27-1.79)$ & $1.08(0.48-2.39)$ & $1.04(0.45-2.41)$ & $1.29(0.48-3.52)$ \\
\hline Agriculture & $1.36(0.56-3.30)$ & $0.90(0.33-2.38)$ & $0.92(0.37-2.28)$ & $1.49(0.61-3.71)$ & $2.66(0.92-7.80)$ \\
\hline Others & $0.79(0.27-2.34)$ & $0.66(0.16-2.33)$ & $2.76(0.92-8.63)$ & $1.09(0.36-3.30)$ & $2.64(0.74-9.25)$ \\
\hline \multicolumn{6}{|l|}{ Monthly income (baht) } \\
\hline $5,000-10,000$ & Ref & Ref & Ref & Ref & Ref \\
\hline No income & $3.29(1.18-9.68)$ & $3.44(1.17-10.25)$ & $3.85(1.41-11.01)$ & $6.40(2.22-19.55)$ & $6.58(2.12-20.77)$ \\
\hline$<5,000$ & $1.58(0.66-3.87)$ & $3.06(1.17-8.12)$ & $2.21(0.93-5.33)$ & $2.51(1.04-6.11)$ & $1.97(0.66-5.87)$ \\
\hline $10,001-20,000$ & $0.89(0.43-1.87)$ & $2.41(1.05-5.67)$ & $0.70(0.33-1.47)$ & $0.89(0.41-1.91)$ & $2.19(0.91-5.39)$ \\
\hline $20,0001-30,000$ & $0.61(0.23-1.58)$ & $0.69(0.17-2.31)$ & $1.26(0.47-3.40)$ & $1.17(0.46-3.02)$ & $1.10(0.36-3.40)$ \\
\hline$>30,000$ & $0.48(0.18-1.22)$ & $1.03(0.32-3.10)$ & $0.58(0.22-1.50)$ & $0.90(0.36-2.25)$ & $0.91(0.30-2.77)$ \\
\hline \multicolumn{6}{|l|}{ Relationship with patient } \\
\hline Spouse & Ref & Ref & Ref & Ref & Ref \\
\hline Parent & $0.53(0.20-1.39)$ & $0.80(0.26-2.27)$ & $0.55(0.20-1.48)$ & $1.27(0.48-3.35)$ & $0.47(0.14-1.49)$ \\
\hline Sibling & $0.34(0.14-0.82)$ & $0.73(0.25-1.93)$ & $0.79(0.33-1.86)$ & $1.43(0.60-3.40)$ & $0.31(0.11-0.90)$ \\
\hline Child & $0.44(0.23-0.83)$ & $0.53(0.25-1.08)$ & $0.59(0.30-1.14)$ & $0.64(0.34-1.22)$ & $0.72(0.35-1.48)$ \\
\hline Other & $0.48(0.15-1.50)$ & $1.30(0.42-3.87)$ & $0.41(0.13-1.22)$ & $1.33(0.44-4.14)$ & $0.21(0.05-0.88)$ \\
\hline \multicolumn{6}{|l|}{ Underlying disease } \\
\hline \multicolumn{6}{|l|}{ Diabetes } \\
\hline No & Ref & Ref & Ref & Ref & Ref \\
\hline Yes & $0.48(0.12-1.72)$ & $0.56(0.08-2.47)$ & $1.99(0.50-8.71)$ & $0.91(0.28-2.87)$ & $0.96(0.23-3.77)$ \\
\hline \multicolumn{6}{|l|}{ Hypertension } \\
\hline No & Ref & Ref & Ref & Ref & Ref \\
\hline Yes & $0.94(0.38-2.32)$ & $1.54(0.63-3.65)$ & $1.04(0.45-2.38)$ & $0.53(0.22-1.24)$ & 1.35 (0.53-3.36) \\
\hline \multicolumn{6}{|l|}{ Dyslipidemia } \\
\hline No & Ref & Ref & Ref & Ref & Ref \\
\hline Yes & $2.19(0.72-7.10)$ & $0.92(0.19-3.52)$ & $4.05(1.14-16.50)$ & $2.34(0.79-7.23)$ & $2.18(0.57-7.72)$ \\
\hline \multicolumn{6}{|l|}{$\begin{array}{l}\text { Duration of being caregiver } \\
\text { (years) }\end{array}$} \\
\hline$\geq 1$ (as earlier) & Ref & Ref & Ref & Ref & Ref \\
\hline$<1$ & $0.94(0.53-1.67)$ & $0.81(0.43-1.50)$ & $1.38(0.78-2.45)$ & $1.68(0.95-2.97)$ & $1.68(0.88-3.26)$ \\
\hline \multicolumn{6}{|l|}{ Caregiving time (hrs/day) } \\
\hline$\geq 24$ & Ref & Ref & Ref & Ref & Ref \\
\hline$<24$ & $0.53(0.29-0.97)$ & $0.89(0.46-1.69)$ & $0.50(0.27-0.91)$ & $0.67(0.37-1.20)$ & $0.52(0.25-1.04)$ \\
\hline
\end{tabular}

${ }^{*} \mathrm{p}$-value $<0.05$

Ref=reference 